\title{
Increasing the Rigor of Case Study Evidence in Therapy Research JOHN MCLEOD ${ }^{\mathrm{a}, \mathrm{b}, \mathrm{c}}$
}

\author{
${ }^{a}$ Department of Psychology, University of Oslo, Norway \\ ${ }^{\mathrm{b}}$ Correspondence regarding this article should be addressed to John McLeod, University of Abertay, School of \\ Social and Health Sciences, Bell St, Dundee, DD1 1HG, UK. \\ Email:j.mcleod@abertay.ac.uk \\ ${ }^{\mathrm{C}}$ An earlier version of this paper was presented as part of a panel, " 'Having It All' With Case Studies in \\ Psychotherapy Research: Their Role in Creating Multiple Types of Knowledge" (moderator: Dan Fishman), Society \\ for Psychotherapy Research Annual Conference, Bern, Switzerland, June 2011
}

\begin{abstract}
Over recent years, an increasing number of systematic case-based investigations of the process and outcomes of counseling and psychotherapy has been published. Nevertheless, case study knowledge continues to have a limited impact on therapy training, practice and policy. It is argued that improvement in the status of case study evidence requires further attention to ways of enhancing the rigor of case study reports. Strategies for strengthening the credibility of case study evidence are explored in relation to a range of methodological issues: the design and goals of case study research, quality criteria for evaluating the validity of case study findings, approaches to aggregating the conclusions of sets of cases, and the interpretation of case data. The paper concludes with a call for case study investigators to be active in asserting the value and relevance of this form of inquiry.
\end{abstract}

Key words:cross-case comparison; database; meta-synthesis; methodology; narrative; outcome; pragmatic; quality criteria; theory; validity; case studies; clinical case studies

Historically, the case study method has been used as an approach to inquiry into the process and outcome of psychotherapy since the earliest writings of Freud and his colleagues. The development of increasingly sophisticated strategies of psychotherapy research, in the latter half of the twentieth century, resulted in a widespread view within the research community that the case study method was associated with fundamental methodological difficulties around validity and generalizability, and was to be regarded as a pedagogical tool rather than a source of primary evidence. More recently, the conceptual and philosophical work undertaken by Bromley (1986), Fishman (1999), Flyvbjerg (2001, 2006) and others has provided a strong intellectual rationale for case study methodology. There is now a growing acknowledgement that case studies have the potential to make a valuable contribution to research-based knowledge. Specifically, a good case study provides a distinctive form of practical knowledge that uniquely captures the complexity of naturally-occurring phenomena. It accomplishes this through being based on multiple sources of information; exploring interactions among different processes or factors; and 
describing and analyzing how processes and events unfold over time. In addition, case studies also possess a higher degree of sensitivity to context than is possible using "extensive," "large n," or "group" designs (Seikkula, \& Arnkil, 2006). By telling a story, a good case study also represents a succinct, memorable, and credible way of communicating new information to consumers of research (Stewart \& Chambless, 2010).

There have been many significant developments in the field of case study methodology in recent years, in relation to the use of adjudicational procedures, strategies for using case data to build theory, elaborating ethical frameworks, case comparison designs, and systematic cross-case analysis (i.e., "meta-synthesis" as a qualitative parallel to the meta-analysis method used in quantitative studies)(Iwakabe, 2009; McLeod, 2010). However, compared to the total annual output of counseling and psychotherapy research articles, it is still the situation that relatively few case studies are being published. In addition, within the set of therapy case studies that have been published within the past decade, emergent innovations in methodology have not been consistently adopted by investigators. The present paper offers some suggestions around ways in which the rigor of psychotherapy case study research might be enhanced. The discussion focuses on four key areas: the contrasting goals of different case study designs; criteria for evaluating the validity of case study evidence; strategies for making the most effective use of a cumulative database of case study reports; specific issues associated with the interpretation of case data.

\section{THE CONTRASTING GOALS OF DIFFERENT CASE STUDY DESIGNS}

As with any other methodology, case study method can be applied to different types of research questions. It is possible to identify four broad genres of therapy case study research questions (McLeod, 2010), focusing on outcome, theory-building, the pragmatics of professional practice, and narration. Each of these genres is associated with a different goal or objective, and a particular set of assumptions about what constitutes good-enough case reporting.

Outcome-oriented case study research is concerned with questions such as: How effective has therapy been in this case? To what extent can changes that have been observed in the client be attributed to therapy? At the present time, there exist two sub-genres of outcome-oriented case study inquiry in the field of psychotherapy. The tradition of " $n=1$ " or "single subject" case study research uses time-series analysis of data from outcome and process measures collected over the course of therapy to generate a robust estimate of the nature, degree, and persistence of change within a single case, and the extent to which change can be attributed to specific therapeutic interventions (Morgan \& Morgan, 2009; Morley, 2007). The tradition of the "Hermeneutic Single Case Design" case study method (Elliott, 2002; Elliott et al., 2009) builds on n=1 methodology in two main ways. A rich data set is collected on each case, comprising qualitative as well as quantitative information. Then, data analysis makes use of an adjudicational approach, in which the case record is systematically interrogated from an affirmative position (the client improved and the gains that were observed are attributable to therapy) and a skeptic position (the client did not change, or any improvement that could be observed could be attributable to extratherapeutic factors). The arguments generated from these contrasting positions are then assessed by a team of expert judges, who provide judgments on the degree to which the case falls on a good-to-poor outcome continuum, and the confidence with which they make this recommendation. 
Theory-oriented case study research seeks to explore questions such as: How can the process of therapy in this case be understood in theoretical terms? How can the data in this case be used to test and refine an existing theoretical model, or build a new theoretical framework? In relation to underlying philosophy of science issues, theory-oriented case study inquiry has a special significance, because case-based support or refutation of theoretical propositions provides an important means through which insights from a single case can be generalized to a wider population of cases. There have been several attempts to formalize the role of case study evidence in theory-building. Stiles $(2007,2009)$ has developed a theory-building strategy in which a pre-existing theoretical framework is systematically tested and refined by analyzing the extent to which observations from new cases can be accommodated within it. On a case-by-case basis, the starting-point theoretical formulation becomes gradually more "saturated" with supporting observations, and more differentiated as concepts become more precisely defined or new concepts are added. An alternative approach to theory-oriented case study research in psychotherapy can be found in the work of Hill (1989), in which conceptual understandings that emerge from each of a series of case studies are assembled into an overall theoretical framework or used to address a theoretical question. For example, this research group used a series of contrasting cases to develop a model of the operation of therapist immediacy (Kasper et al., 2008; Hill et al., 2008). A further strategy for generating theory has been to compare goodoutcome and poor-outcome cases, as a means of identifying factors that may be responsible for success or failure in therapy (for examples, see Strupp, 1980; Watson, Goldman, \& Greenberg, 2007; Watson, Goldman, \& Greenberg, 2011; Goldman, Watson, \& Greenberg, 2011).

Pragmatic case studies address questions such as: What was the overall "guiding conception" used by the therapist in this case, and how was this related both to the individualized case formulation employed and to the strategies and methods utilized? What did the process of therapy descriptively look like? Which therapeutic strategies and interventions made a positive contribution to outcome, and which ones were harmful or hindering? The primary goal of a pragmatic case study is to generate a detailed representation of how a specific therapy approach has been deployed with a specific client. Pragmatic case studies are similar to traditional clinical case reports, in so far as the therapist is usually the main author of the account of the case that is provided. However, unlike traditional clinical case reports, there is a requirement on the part of the author to provide a wider array of basic quantitative and qualitative information about the case, and to adhere to a standard format. Examples of pragmatic case studies are published in Pragmatic Case Studies in Psychotherapy, Clinical Case Studies, and other journals. One of the most important objectives of this type of case study is to contribute to the construction of an extensive database of cases that can be used to inform practice.

Experiential or narrative case studies aim to tell the story of the case, from the perspective of the client or therapist. These case studies explore questions such as: What was it like to be the client or therapist in this case? What was the meaning of this therapeutic encounter? While this form of case study represents the most direct and straightforward means of depicting what can happened within therapy, relatively few cases of this type have been published. Examples of narrative case studies include Etherington (2000) and Dinnage (1988).

These four genres of case study inquiry (outcome-oriented, theory-building, pragmatic, and narrative) can be regarded as "prototypical" case study designs. There are many therapy case 
studies published in leading journals that incorporate elements of more than one of these formats. For example, almost all therapy case studies offer some level of narrative account of the experience of the therapist or client. Similarly, many outcome-oriented, pragmatic, and narrative case studies encompass some degree of reflection or discussion around the theoretical implications of the material that has been presented. At the same time, it is hard to identify any therapy case studies that have been successful in fully addressing more than one type of question. Given the structural requirements and length constraints of journal articles, it is necessary to organize case material around one main research goal or question. Case studies that do not clearly identify a single goal tend to be frustrating to read, because they fail to "deliver" on any of these core dimensions of case study knowledge. It may be that monograph-length case reports (which are characteristic of ethnographic research) might enable therapy case study authors to embrace all four dimensions in an adequate fashion, but this possibility remains to be demonstrated.

At this point, the suggestion that there are four distinct forms of therapy case study investigation needs to be regarded as no more than a preliminary and tentative suggestion for organizing this field of inquiry. It may be that other commentators are able to identify additional case study genres, or are able to collapse these four types into a smaller set. My own view is that these distinctions are useful because they help case study investigators to be clear about what they are trying to achieve. These dimensions are also valuable because they carry important implications around how to enhance the rigor of therapy case study research. The following sections explore the ways that these contrasting types of therapy case study are associated with different quality criteria and different strategies for meta-analysis.

\section{CRITERIA FOR EVALUATING THE VALIDITY OF CASE STUDY EVIDENCE}

For researchers with an interest in case study methodology, there are valuable lessons that can be learned from consideration of developments within the field of qualitative research in counseling and psychotherapy. Until the 1980s, few qualitative studies were being carried out by therapy researchers. Then, once counseling and psychotherapy researchers started to appreciate the potential of qualitative methods and conduct such studies, they came up against barriers to publication, in the form of reviewers and journal editors who were (often justifiably) concerned about the methodological quality of qualitative manuscripts that were being submitted. The process of challenging and dismantling these barriers required a sustained effort on the part of leading figures in the area of qualitative psychotherapy research, who painstakingly compiled validity criteria and publication guidelines for qualitative research (e.g., Elliott, Fischer and Rennie, 1999; Morrow, 2005; Stiles, 1993) that came to be widely accepted across the research community. In turn, the existence of these methodological standard-setting statements motivated qualitative researchers to plan and conduct studies that were more rigorous. These guidelines also served to boost the numbers of qualitative studies that were carried out, by giving researchers and dissertation committees more confidence in the quality and eventual publishability of work that was being proposed. 
It would be valuable to develop specific and detailed quality criteria for case study research in counseling, psychotherapy, and related disciplines, in similar fashion to the more general qualitative research guidelines developed by Elliott, Fischer and Rennie (1999). Such an endeavor would need to steer a line between (a) constructing an enabling framework that encouraged best practice, and (b) imposing requirements that inhibited case study inquiry in settings in which practitioner-researchers might be faced with organizational and institutional constraints on the amount and type of data that they could collect. One possible strategy for the development of case study quality criteria might be to make a distinction between core criteria, which would apply to all forms of therapy case study research, and specific criteria, which would apply to particular genres of case study inquiry. General criteria might seek to identify acceptable standards on the provision of information in areas such as:

- the aims and objectives of the study

- the characteristics of the problem presented by the client(s), described in such a way that it is possible to locate the case within a wider population

- the organizational or agency context within which the therapy took place

- number of sessions, missed sessions, length of sessions, payment, etc.

- characteristics of the therapist (e.g., age, gender, training)

- interventions used by the therapist

- ethical procedures used to obtain client consent

- use of external supervision and consultation by the therapist.

This kind of information is required in case reports published in Pragmatic Case Studies in Psychotherapy and Clinical Case Studies, but is not always supplied in case studies that appear in other counseling and psychotherapy journals. However, even in specialist case study journals, there can be issues around the level of detail that is provided in each of these areas. For example, most readers of therapy case studies are interested in the methods and interventions used by the therapist. A minimal description of therapist interventions might merely name the general orientation of the therapist. A more adequate account might describe how the therapist used this model, including how it was adapted in response to client preferences. An even more detailed account might specify interventions in terms of a validated taxonomy, such as in cognitive behavior therapy (Persons, 2008). The importance of basic factual information about the client, therapist, and context, and the nature of the therapy intervention, is highlighted in case reports where this information is not adequately reported. These absences distance the reader from the case, and make it harder for the reader to make connections with their own practice or with other cases.

It is possible to identify further quality criteria that are associated with each of the four genres of therapy case study research introduced above. For example, in outcome-oriented case studies, it is valuable to consider the relevance of extra-therapy events in the client's everyday life that may have influenced the course of therapy, and to make use of some form of time-series 
analysis that allows identification of causal links between specific interventions or stages in therapy and specific shifts in client functioning. A good outcome-oriented case study will also draw upon more than one source of outcome data. In a theory-building case study, it is necessary to collect data that are relevant to the theoretical constructs that are being examined. It is important to note that both outcome-oriented and theory-building case studies are likely to be undertaken by researchers with an allegiance to a particular theory or therapy approach. Thus the credibility of such studies is enhanced if the expectations and involvement of members of the researcher team have been self-critically addressed, alternative interpretations of data have been systematically considered, and some form of independent external auditing of data analysis has been incorporated. In addition, the internal validity of outcome-oriented and theory-building case studies is strengthened if there is clarity and transparency around the process of data analysis, so that readers can understand how categories or conclusions are grounded in observations.

Quality criteria that are relevant to pragmatic case studies are specified in detail in the guidelines that are available for authors of papers submitted to the Pragmatic Case Studies in Psychotherapy journal. Even here, however, there are some areas in which additional criteria might be worthy of consideration. In many pragmatic case studies, the person of the therapist, and his or her experience in relation to working with the case that is being reported, is given relatively little attention. These cases read as though the therapy consists of the delivery of a well-defined therapy protocol. This lack of information about therapist experience and qualities makes it hard to use pragmatic case study evidence to expand our understanding of the practical manifestation of concepts such as counter-transference or therapist congruence/authenticity, or to make connections with the expanding literature on therapist effects. Another area in which pragmatic case studies can be disappointing is in the extent to which information is provided about the use by therapists of formal and informal clinical supervision, peer consultation, personal therapy, prayer, meditation, reflecting teams, and other sources of support and guidance. The absence or under-reporting of this type of information not only perpetuates an individualist conception of therapy, but also acts as a barrier to the development of an appreciation of how supervisory and consultative processes operate at the case level.

The development of quality criteria that might be applicable to narrative case studies needs to draw on basic common sense and sensitivity. At its heart, a narrative case study is a personal statement, and it is essential to be willing to respect the decisions of the author in terms of what he or she wishes to report, and the kind of narrative structure that he or she finds most meaningful. What most readers are looking for in a narrative case study is a sufficient degree of emotional authenticity to allow them to enter into the experience of the therapist or client (or both). Within the field of qualitative research, there are many ideas and procedures that have evolved within the tradition of autoethnographic inquiry (McLeod, 2011) that might usefully be applied in narrative case studies. For example, keeping a diary or record of experiences as they occur makes it possible to write in a way that captures emotional and experiential detail that may be lost to a purely retrospective account. In some situations, the engagement of the narrator in dialogue with others may help him or her to articulate aspects of personal experience that might otherwise have been hidden.

The case study quality criteria that have been introduced here need to be viewed as preliminary and tentative. During the process of compiling a general set of quality criteria for 
qualitative research, Elliott, Fischer and Rennie (1999) consulted widely across the qualitative research community. Such an exercise would be valuable in relation to the development of more specific quality criteria for therapy case study research. However, it would also be useful to go beyond the research community, and elicit the views of practitioners and policy-makers who are consumers of case study knowledge, around the features of case study reports that increase or diminish their confidence in the credibility of what they are reading.

\section{STRATEGIES FOR MAKING THE MOST EFFECTIVE USE OF A CUMULATIVE LITERATURE OF CASE STUDY REPORTS}

\section{Meta-Synthesis}

It was not until the 1970s that a substantial number of controlled comparative group studies, e.g., randomized clinical trials, of the outcomes of counseling and psychotherapy began to be available. At that point, the development of the technique of statistical meta-analysis made it possible to make well-founded statements about the effectiveness of various types of therapy that were based on findings from multiple studies. This shift hugely amplified the impact of therapy outcome research on practice, training, and healthcare policy. The findings from a single controlled outcome study, even if it has a large sample of clients and comes up with clear-cut results, is always open to question on the grounds of situational factors, such as the particular therapy setting, the measures that were used, the characteristics of the therapists, the allegiances of the research team, and so on. The introduction of meta-analytic reviews made it possible to address most of these issues. The field of case study research in counseling and psychotherapy is now at a stage where a reasonably large number of rigorous case studies are available. A central priority, therefore, is to develop a credible strategy for acquiring knowledge from multiple cases, such as the "meta-synthesis" method (Iwakabe, 2009) mentioned above and discussed below.

The development of an agreed set of quality criteria for therapy case study research represents an essential first step in the construction of a means of aggregating or combining the findings of case studies. Statistical meta-analysis of quantitative outcome studies of therapy always begins by setting a quality threshold for inclusion of relevant studies. In similar fashion, it is necessary to make sure that reviews or meta-syntheses of case study evidence are based on studies that have attained an acceptable level of rigor.

It is possible for case study researchers to borrow some aspects of statistical metaanalytic procedures. In case studies where standardized outcome measures have been used, it is possible to generate Effect Size (ES) statistics, and to calculate whether clinically significant and reliable change has been reported (Kromrey \& Foster-Johnson, 1996). It is also possible then to aggregate the findings of $n=1$, single subject case studies, in the form of meta-analysis (Faith, Allison, \& Gorman 1996; Van den Noortgate \& Onghena 2003). However, this kind of review strategy is only likely to be convincing in situations where the cases that have been included can be shown to be representative of a wider population. In an RCT, the research design is based on a sampling strategy that makes it possible to argue that the ES that is found is a reasonable approximation of the ES in the majority of cases of that type of therapy. By contrast, many case studies that are published are chosen on the basis that they give a clear-cut positive result: they are demonstrations of what a particular approach may be capable of, not of what it generally is 
capable of achieving. Another problem with statistical summation of case study findings is that this approach rather misses the point of doing a case study in the first place. Why go to all the trouble of carrying out a case study, if the only information that is used is the ES statistic or the clinical/reliable change index (Jacobson \& Truax, 1991) for the case? In summary, although it is useful to report ES and clinical/reliable change figures in case reports, as a way of positioning the case within a broader context of available benchmarks (see, for example, Elliott et al., 2009; Hougaard et al., 2008; Hougaard, 2008), it is important for the case study research community to develop other strategies for aggregating the findings of case reports.

There has been relatively little discussion within the therapy case study literature around the issue of adapting the logic of meta-analysis to case study evidence. An important contribution has been made by Shigeru Iwakabe, who has the advantage of being based in Japan, where the psychotherapy community has tended to prioritize case study evidence ahead of other sources of knowledge about the process and outcomes of therapy (Iwakabe \& Gazzola, 2009; Iwakabe, 2011). Iwakabe \& Gazzola (2009) identified three strategies for aggregating knowledge across case studies: (a) a case database that can be searched by clinicians to allow them to access cases that may be of interest (e.g., a therapist starting treatment with a new client with Asperger's Syndrome might find it useful to read about how other therapists had approached the task of offering therapy to similar clients; (b) application of techniques from qualitative "metasynthesis" (mentioned above) to allow common themes to emerge over a set of cases; and (c) case comparison in which cases that are closely matched on some criterion are analyzed in terms of similarities and differences in what has been helpful and hindering. Iwakabe (2011) discussed the case comparison method in more depth in relation to some published examples of the use of this approach. Some suggestions around enhancing the rigor of these strategies for case study meta-synthesis are offered in the following sections.

\section{Developing a Therapy Case Study Database}

The construction of a comprehensive therapy database of case examples is a vision that is hugely appealing to many of those who are active in the field of counseling and psychotherapy case-based inquiry. The promise and potential of a database is that it would give access to knowledge that was explicitly grounded in what actually happens within everyday practice. However, at this point in time the reality is somewhat frustrating. While there are probably more than 500 therapy case studies that have been published (Iwakabe \& Gazzola, 2009), these studies are of variable quality. Many of them lack credibility because insufficient information is provided, or because the author appears to be using the case report to promote his or her own model of therapy. It is also hard for potential readers to locate many of these cases, or to gain access to full-text copies of them, especially in an open access manner. As a result, although the possibility of a case study database of proper size size that can be accessed by practitioners is close, it does not yet exist in any practical form.

It is likely that many of these practical barriers will be resolved within the next 5-10 years. There are now almost 40 high-quality, systematic therapy case study reports available online within the present journal, which is open access. The considerable social and governmental pressure that has built up around allowing open access to research knowledge is gradually resulting in more and more journal articles being available to general readers. The expanding 
network of therapy practitioners and researchers with an interest to case study methodology means that, at some point, someone will launch a comprehensive on-line database of therapy case studies. But what happens then? What would we do with such a database?

I believe that there are two key functions that need to be undertaken in order to maximize the value of a database of systematic and rigorous case study evidence: stewardship, and training. A central, consolidated therapy case study database might have similarities to a wiki site-contributors might upload case study reports, or summaries of case studies that had been published in journals or other outlets. Just as in the Wikipedia on-line dictionary, and other wiki sites, it would be necessary to monitor contributions for offensive, mischievous, or unethical content. Beyond this, it would be helpful if those tending for the database were to review content on a regular basis and issue calls for additional material. For example, it is probable that the majority of cases that have been (or will be) written are reports of successful therapy. It might be helpful, therefore, if the stewards of the database were to offer encouragement or guidance to practitioners to submit poor-outcome or ambiguous-outcome cases. In addition, regular audits of the number of cases categorized by client group or type of therapy would certainly make it possible to identify areas of practice that were under-represented in the database. Users of a database would also be interested and incentivized through learning about the "ten most downloaded cases," lists sent in by readers of their favorite cases, or indicators such as "readers who enjoyed this case went on to read...”. These are techniques that have been used to good effect by Amazon.com and other commercial websites.

A case study database would be an open system, one that enabled users to sample information in whatever way made sense to them. It is probable that at least some potential users would be inhibited by the sheer amount of information that confronted them, and might not feel confident about how to critically analyze case study findings or use case-based knowledge to inform their practice. It will be useful to provide examples of how colleagues have exploited the database, and to offer training experiences on how to navigate it. Research on practitioner experiences and perceptions of a case study database, and how they had made links between case material and their practice, could also be carried out. The history of the therapy treatment manual movement represents an area of practice-relevant psychotherapy research methodology that is relevant to the field of case study research. Psychotherapy treatment manuals began to be published in the 1970s and 1980s, and were soon widely adopted within controlled research studies and as protocols to guide routine practice and training. However, it became clear that there were major differences in "usability" and perceived relevance of manuals, from the point of view of clinicians. Research into practitioner experience of therapy manuals, and their suggestions for how better manuals might be constructed (Addis \& Krasnow, 2000; Duncan, Nicol, \&Ager, 2004; Najavits, Weis, Shaw, \& Dierbeger, 2000) have provided a valuable basis for enhancing the rigor of second-generation manuals. Similar research could be carried out into practitioner experiences of reading and using case study evidence.

An important potential feature of a case study database would be a facility for readers to make comments on cases and make ratings of dimensions of case quality. The Pragmatic Case Studies in Psychotherapy journal has taken a step in this direction by publishing invited reviews and commentaries on articles. It seems clear (although it would be valuable to research this through a reader survey) that this approach introduces a dialogical aspect to the experience of 
journal readers, and makes it easier for them to engage with the material. An open review/commentary facility (as in the Amazon.com "Tripadvisor" or the London Guardian "Comment is Free" pages) would open the dialogue to a wider range of voices and positions. My prediction is that such a facility would encourage busy practitioners to visit a database, and would also serve as a driver of quality through allowing authors to gain a better sense of what "worked" (or not) for their readers.

\section{Qualitative "Meta-synthesis" of Cross-Case Themes}

There are several well-established approaches to carrying out systematic analyses across cases - i.e., meta-syntheses - of the findings of qualitative and mixed methods studies (see, for example, Timulak, 2007, 2009). There is obvious merit in applying these procedures to assemblages of therapy case study reports. This undertaking might involve, for example, collecting all the available, good quality case studies into psychoanalytic and psychodynamic therapies for depression, and using methods of qualitative meta-synthesis to identify themes that appeared across the set of studies as a whole. A review published in Japan by Iwakabe (2006; Iwakabe \& Gazzola, 2009) examined common processes that could be identified in long-term, psychodynamically oriented eclectic psychotherapy with young adult clients with interpersonal difficulties. The findings of the review included significant themes that had not been extensively discussed in the existing theoretical literature. A similar exercise, designed and conducted at a time before the methodology of qualitative meta-synthesis was developed, was the psychotherapy research project of the Menninger Foundation (Wallerstein, 1986, 1989).

Another strategy would be to use meta-synthesis cases to generate an understanding of the therapeutic principles that are supported or suggested by a set of case reports. This approach would be consistent with the idea of evidence-based practice being built around sets of therapeutic principles, rather than around manualized treatment packages (Levitt, Neimeyer, \& Williams 2005). Meta-synthesis of therapeutic principles would be made easier if authors of case studies attempted to identify the principles that were supported in a case (see Levitt, Butler, \& Hill 2006, for an example of how principle-based conclusions can be generated in a qualitative study). However, even if the authors of a case study did not identify therapeutic principles, it would be possible for two or three readers to make independent ratings of a published case study, and arrive at an agreed list of supported principles, along with confidence ratings.

Principle-based meta-synthesis could be organized around categories of client problem (e.g., PTSD or schizophrenia), or other important dimensions, such as client ethnicity or gender. An example of how this type of meta-synthesis would be to examine the therapeutic principles that are highlighted in case reports of therapy with clients diagnosed as schizophrenic. Taking, as a starting point, two such studies published in the present journal, Atwood (2012; two cases) and Karon (2008; single case), there are some therapeutic principles that can be identified in all three of these cases, such as using frequent meetings at the start of therapy to develop trust, therapist willingness to make a commitment to long-term therapy, and assuming that all client statements have meaning in relation to their life experience. There are also some principles that appear in some cases and not others, such as flexibility around location of meetings (Karon, 2008) and explicit articulation of a therapeutic plan (Atwood, 2012). The addition of further cases would make it possible to determine which therapeutic principles seem to represent universal 
characteristics of effective work with this client group, and which principles seem to be less central. Concerning less frequently reported principles, further analysis of case material could make it possible to identify the specific circumstances within which these strategies might be most, or least helpful.

Meta-synthesis in terms of themes, categories, or principles are analytic strategies that involve the identification of dimensions along which each case has been found to vary. This approach has been widely adopted within North American qualitative research. Ultimately, it is an analytic procedure that seeks to highlight cross-case similarities, and to downplay unique or distinctive patterns or features that may occur within individual cases or sub-sets of cases. An alternative strategy, that has been espoused within some German-language qualitative research communities, has been to identify "ideal type" or "prototypical" cases (McLeod, 2011; Stuhr, \& Wachholz, 2001). From a case study perspective, ideal type analysis has the advantage of retaining the "caseness" of the data, rather than dismantling cases into themes and categories. There may also be practical benefits associated with meta-syntheses that generate descriptions of "types" of clients, because it seems likely that practitioners tend to reflect on their work in terms of configurations or gestalts of features that represent "types" of clients, or typical therapeutic trajectories. At the present time, the use of ideal type analysis in qualitative research on therapy has been based on data from interviews (see, for example, Frommer et al., 1996; Kuhnlein, 1999). To my knowledge, no one has attempted to carry out an ideal-type analysis of a group of published case study reports.

The further development of a methodology for qualitative meta-synthesis of themes that emerge across sets of therapy case studies might involve making creative use of the difference in emphasis among various case study genres. For instance, there exists a tension between narrative case studies, which reflect a personal point of view, and other genres of case study (outcomeoriented, theory-building and pragmatic), which seek to present comprehensive and detached accounts of cases. Narrative case studies are inevitably selective, reporting what seemed most important to the author. "Systematic" case studies, on the other hand, have a tendency to want to fit a case into pre-existing theoretical and professional categories. Careful consideration of themes emerging from narrative cases therefore acts as a safeguard against the risk that cumulative case study knowledge might merely function as a vehicle for perpetuating dominant assumptions and ideologies. Thus narrative case studies serve a heuristic function in generating a constant stream of new ideas that then need to be verified in more systematic investigations (which may include "large-n" or group studies as well as case studies).

There are certain distinctive advantages of theory-building studies that are typically not captured in outcome-oriented studies. Two of the major accomplishments of contemporary therapy case study research have been the use of case study methodology to develop a theory of the links between therapy and the everyday life of the client (Dreier, 2008) and to construct a theory of the process of assimilation of problematic experience in therapy (Stiles, 2002). Each of these research programs has been able to demonstrate how attention to processes that occur at a case level makes it possible to identify factors that are intrinsic to outcome, that are not readily accessed or observed through group-level measurement tools. In each of these areas, theorybuilding case research presents a direct challenge to anyone seeking to analyze therapy outcomes. The work of Dreier (2008) demands that those conducting outcome-oriented case 
studies should look seriously at everyday life experience as a source of learning and change. The work of Stiles demands that shifts in level of assimilation of a problematic experience should be considered (alongside shifts in client behavior and symptoms) as an important indicator of change.

The adoption of a "principle-oriented" perspective, ideal type analysis, and the heuristic use of different genres of case study represent ways in which methods of qualitative metasynthesis can be adapted to the field of counseling and psychotherapy case study research. Techniques of qualitative meta-analysis have evolved in research domains that are less immediately linked to practice, and less likely to be shaped by powerful ideological/theoretical assumptions about practice. In addition, the majority of qualitative studies being synthesized are commensurable in terms of basic method, by virtue of comprising interpretive-phenomenological analyses of data from semi-structured interviews. Counseling and psychotherapy case study research comprises a distinct area of inquiry. While methods of qualitative meta-synthesis have a great deal to offer to therapy case study research, it might be wise to apply them in ways that acknowledge the unique challenges and possibilities associated with the therapy case study tradition.

\section{Case Comparison}

One particularly valuable method of moving from the unique insights arising from an individual case, to being able to make more general statements derived from case data, is the use of a case comparison strategy. A case comparison study takes a pair of case studies that are similar in many respects, but different in one significant respect, and seeks to use the contrast between the cases to generate an understanding or explanation of the factors that contributed to the different outcome. Within counseling and psychotherapy case study research, this approach has mainly been employed in relation to comparisons between good-outcome and poor-outcome cases. In principle, however, the case comparison method could be used to investigate other dimensions of contrast, such as cases with similar good outcomes but with very different therapy processes or being based on different models of therapy.

The technique of case comparison was first used in a systematic way within psychology by Henry Murray and his colleagues, who built up a theory of personality by analyzing a single case, then comparing the conceptualizaton that emerged from that case against the patterns that were observed in a subsequent case (Murray, 1938; Murray \& Morgan, 1945). This is essentially the same strategy that has been adopted by Stiles $(2002,2009)$ in a program of research into the assimilation model of therapeutic change. These research programs have, over a considerable period of time, made use of an extensive series of case studies, each of which served as a basis for case comparison. This strategy is similar to the technique of "constant comparison" that is employed in grounded theory analysis of qualitative data (Corbin \& Strauss, 2008). In grounded theory analysis (and other versions of qualitative data analysis) each new example of a theme or category is compared against all previous examples, in a way that contributes to reinforcing the significance of the initial theme or category, or leads to a differentiation into sub-themes or subcategories. 
Other than the early work of Wallerstein $(1986,1989)$, the use of case comparison within therapy case study research has been based on pairs of cases, or a limited set of cases. These investigations have tended to start with a comparison between a good-outcome and a pooroutcome case, drawn from a larger set of cases in which clients have been exposed to the same form of therapy, and where a standard array of data is available for each case. In a review article, Iwakabe (2011) discusses five published cross-case comparison projects, and arrives at two main conclusions. First, he suggests that this form of case comparison is capable of generating significant insights into the factors that contribute to the outcomes of therapy. Second, he points out that the task of systematic case comparison is in fact extremely taxing for any researcher or research team, because of the vast amount of information that is available for each case. Iwakabe (2011) identifies a range of strategies, such as identifying key events or stages in therapy, that have been used in case comparison projects to reduce or condense case data into a manageable form. Nevertheless, Iwakabe (2011) reflects that, for him, questions remained around additional factors, not taken into account within the case comparison process, that might have had an equal, or greater, influence on outcome.

It seems reasonable to conclude that the method of case comparison has an important role to play within a broader movement toward aggregating case study findings. However, it is also necessary to find ways to enhance the rigor of case comparison methodology. One straightforward way in which additional rigor might be introduced into case comparison reviews would be for authors to be explicit about the procedures that they implemented within the review process, and the measures that they adopted to minimize bias. Several of the studies discussed by Iwakabe (2011) did not include a "method" section in which these procedures were described and justified. In the absence of such information, it is difficult for readers to assess the validity of conclusions, or for subsequent authors of case-comparison reviews to build on previous good practice. One approach that has a lot of potential in relation to enhancing the rigor of case comparison projects is to adopt some form of adjudication procedure. The use of different teams of researchers to arrive at alternative analyses or "readings" of case data was pioneered by Murray, and has been further developed by Bromley, Elliott, Miller, Bohart, and others. A comprehensive discussion of current ideas about adjudicational procedures within therapy case study research can be found in a special issue of the present journal (Fishman, 2011).

It may also be valuable for therapy researchers to look at the ways in which case studies are handled in other academic disciplines. For example, a wide range of ideas about how to undertake rigorous case comparison are contained in an edited collection by Diamond and Robinson (2010a,b), which brings together several examples of how historians, geographers, and other social scientists have set about making use of the existence of "natural experiments" to deepen their understanding of causal factors in social, cultural, and economic change. One of the natural experiments that is discussed considers the question of how habitation by people from the same cultural background resulted in the eventual ecological destruction of some Polynesian islands (e.g., Easter Island) as compared to the continued long-term sustainability that has occurred within other island environments (Diamond, 2010).

Another natural experiment looks at the consequences for a society and its economy in Africa of differences in regional intensity of slave trading (Nunn, 2010). Most of the case comparison studies reported in Diamond and Robinson (2010a) are based on data from multiple 
cases (more than 80 cases in the Diamond [2010] analysis). While these cross-case analyses do not draw on a single unified methodology, it seems clear that there are some underlying principles that are apparent. Compared to therapy cases, the basic case data that is available to these historians and social scientists is much more comprehensive and detailed. For example, in his study of the implications of patterns of slave entrapment, Nunn (2010) was able to draw on studies of the process through which slaves were captured (often through betrayal by members of their own family), and the impact of these processes on post-slavery social arrangements. Because of the amount and complexity of information that is available, it is impossible for the author of this type of cross-case analysis to hold all of the data in his or her head, and arrive at an intuitively-derived conclusion. Instead, rules need to be developed through which data can be coded and summarized in a master database. In terms of identifying causal patterns within the data, each of these studies made a distinction between initial conditions (before the "intervention" occurred) and the narrative sequence of events that could be observed postintervention (Diamond and Robinson, 2010b). Finally, rigorous cross-case analysis required an interdisciplinary team of analysts, who were able to challenge the assumptions made by their colleagues, and to make use of specialist knowledge of particular aspects of the data. The outcomes of the systematic analysis of these "natural experiments" are striking, in that they arrive at conclusions that differ from the prevailing wisdom. For example, Nunn (2010) was able to show that patterns of present-day prosperity in Africa are predicted by prior intensity of slave trading (those areas where there was less slave trading have the highest living standards). Diamond (2010) found - to his surprise - that the ecological devastation of Easter Island and other similar habitats could not be explained by cultural patterns, such as being obsessed by building large statues) but instead was a result of environmental damage .

In the context of therapy cross-case analyses that have been carried out, the studies reported in Diamond and Robinson (2010) are significant because they draw on primary case study reports that were initially compiled by a wide range of researchers. Up until now, therapy cross-case comparisons have been restricted to contrasts across cases where data were collected and analyzed by a single researcher or research team. Being able to use standardized data makes cross-case analysis easier, but it also introduces a powerful source of bias because the choice and collection of data are necessarily shaped by the pre-existing assumptions of those who designed the study. Where a more diverse set of cases is used, it is much less likely that that data will reflect a single point of view. What Diamond and Robinson (2010a) and their collaborators have shown is that it is possible to develop reliable and valid ways of integrating non-commensurable case reports into a single data set that can then be interrogated using both qualitative and quantitative analytic techniques.

\section{SPECIFIC ISSUES ASSOCIATED WITH THE INTERPRETATION OF CASE DATA}

A basic assumption that underpins the approach taken in this paper is that high quality therapy case study reports are based on rich case records that incorporate multiple sources of information. There are no fixed rules for finding meaning and identifying patterns in complex case data-it is always a matter of engaging in a process of interpretation in which alternative understandings or explanatory accounts are systematically tested against the data that are 
available. The achievement of a plausible interpretation is facilitated by the use of a team of analysts. Although such a team can be organized and configured in different ways, its function is to enable the widest possible dialogue among competing perspectives on the material. The ideas for enhancing the rigor of therapy case study research, discussed in earlier sections of this paper, merely represent potential strategies for extending the scope of interpretive practice in this area of inquiry. In this section, I would like to highlight two specific issues that seem to me to be inherent in any attempt to make sense of therapy case study data: multiple causality of outcomes, and the existence of client and therapist meta-narratives. These issues represent major challenges for which I do not have any particular solutions.

\section{Multiple Causality of Outcomes}

The issue of multiple causality of outcomes refers to the fact that both client and therapist are usually engaging in a multiplicity of activities that they hope will result in amelioration of the client's problems. For example, a therapist may put a lot of time and effort into devising and facilitating a homework assignment for a client. However, at the same time, the therapist is listening to the client, is responding in ways that are attuned to the client's pace and language, is maintaining professional boundaries, is conveying hope, and many other things. On his part, the client may be taking the homework seriously, but could also be involved in covert processing of thoughts and feelings that are not disclosed to the therapist, or might be beginning to structure the rhythm of his week around the therapy session, or could be processing the content of the session with his partner when he goes home. If this client and therapist have taken part in a case study, it is possible that weekly symptom ratings might show a pattern of improvement that coincides with the start of the homework episode. But does this mean that the homework had a causal role in relation to these changes? This is a hard question to answer, because the homework activity existed in the context of multiple other activities that were also focused on creating positive change, and presumably all played some part in what happened. One of the main reasons for undertaking therapy case study research is to try to develop a concrete, grounded appreciation of what it is in therapy that makes a difference. The homework example offered here suggests that there are risks in the use of time-series analysis as a basis for identifying causal sequences in therapy case studies. The risk is that the case analysis will highlight the significance of salient observable events within the case, and downplay the significance of the many other processes that operate in the background.

The problem of multiple causality arises because there are many processes and activities moving in the same direction. It is probably much easier to identify, with some confidence, the occurrence of negative causal sequences, which may often comprise a single event or characteristic that is, so to speak, pushing in the other direction. Unfortunately, relatively few poor outcome cases have been studied, and clients with good outcomes do not appear to mention such episodes when they are interviewed. In their analysis of a poor outcome case of a client who participated in Emotion-Focused Therapy, Watson, Goldman, and Greenberg (2011) were able to demonstrate detailed evidence of several occasions in therapy in which the client was not able to be aware of, and process, his own feelings. These episodes were readily identifiable, and they stood out against the background context of multiple helpful activities being undertaken by a skilled and caring therapist. In terms of the overall analysis of the case, it was possible for Watson, Goldman, and Greenberg (2011) to develop a comprehensive account of how these 
negative sequences arose from both proximal and distal experiences in the client's life (i.e., what Diamond and Robinson, 2010a refer to as "initial conditions").

Another example of the explanatory potential of negative therapeutic experiences can be found in some of the narrative case reports of poor outcome cases (in fact, examples of abusive practice) included in Bates (2006). A common theme across these cases was a pattern in which therapy was initially helpful for the client, but that at a later stage the therapist persisted, against the wishes of the client, in using interventions that the client experienced as harmful. The studies by Bates (2006) and Watson, Goldman, and Greenberg (2011) suggest that therapy case study research may have an important role to play in developing a comprehensive theory of what can go wrong in therapy. This kind of knowledge may be highly valuable for the profession. Therapists tend to have a fairly good idea of how therapy tends to unfold when things are going well, but to be much less aware of what is happening on occasions where they "lose" their clients (Hannan et al., 2005; Hatfield et al., 2010).

\section{Client and Therapist Meta-Narratives}

A further challenge that emerges in interpreting rich case data is that the product of the interpretation always represents some sort of story. The narrative construction of case-based evidence is further complicated by the fact that the primary data will often incorporate the client's narrative account of his or her experience in therapy, and the therapist's account. My own personal view is that the client's account of what happened is an essential element of any systematic case report. The interpretive dilemma here is that the narrator inevitably organizes his or her account in terms of some kind of pre-existing "meta-narrative" structure (McLeod, 1997).

There is evidence from several studies that, when asked to recount the story of their therapy, people create narratives that locate the events of therapy within a rhetorical framework that reflects essential aspects of their personal worldview, attributional style, and sense of identity. For example, Adler \& McAdams (2007) asked former therapy clients to write accounts of their therapy experience, and found that some of them constructed narratives around a theme of personal agency ("this is how I overcame my depression") while others constructed more relational narratives ("this is how my therapist and I worked together"). Kunhlein (1999) and Valkonen, Hanninen, and Lindfors (2011) found that some clients, both before they entered therapy and then again at follow-up, accounted for the meaning of their therapy in terms of resolving longstanding developmental-childhood problems, whereas others adopted a perspective from which therapy was viewed as a matter of acquiring skills to enable them to cope with current situational difficulties.

The relevance of these narrative structures to the task of making sense of case data can be illustrated through consideration of the "case of George,", which is one of the most thoughtfully and rigorously analyzed cases within the therapy case study literature (Elliott et al., 2009). The account offered by George himself clearly reflects an agentic, situational narrative form. However, many readers might find themselves making sense of the experiences that George describes as falling more easily into a relational-developmental narrative. The Elliott et al. (2009) study makes a major contribution to the field of therapy case study research by including sufficient primary data to enable readers to arrive at conclusions that may not entirely coincide 
with those of the client or the research team. But the underlying methodological dilemma remains - how can we create rules or strategies for the interpretation of case data that take account of meta-narrative structures? In most case study reports, the most salient and dominant meta-narrative structures are those imposed by the author (in many cases also the therapist). I cannot be the only case study reader who has wished that the author would loosen up on reporting phenomena that were consistent with his or her espoused theoretical model, and let me see the more complex data on what it was that was actually happening. The tendency for case study investigators to impose their own assumptions and conceptual categories on the data was recognized by Murray (1938), who invited non-psychologists into his research clinic, and valued their capacity to offer alternative ways of understanding case material.

\section{CONCLUSIONS}

This paper represents an invitation to curiosity, creativity, and dialogue around the methodology of therapy case study research. Methodological innovation and rigor are not topics that necessarily hold much excitement for case study researchers, who primarily tend to be interested in using case-based inquiry as a means of getting close to the realities of practice. It is important to keep in mind that it took decades of sustained effort to arrive at the level of agreement around methodological quality and rigor that currently exists in areas of research such as randomized clinical trials, or the use of outcome measures. Articles such as the present paper, which make suggestions about possible areas for further methodological work, need to be supplemented by actual studies that explore different approaches to case study meta-synthesis, or experiment with new procedures for analyzing case data. It is inevitable that some of these attempts will appear, in time, to be methodologically naïve. But the only way to drive forward methodological innovation is to try out new approaches, and trust that readers and critics will come up with better solutions.

A final aspect of the push to integrating the findings of case studies into the evidence base for counselling and psychotherapy is to be more willing to assert the relevance of casebased evidence. In many therapy case reports, the conclusion will include a statement along the lines of, "It is not possible to generalize from a single case, the findings of this case study need to be confirmed through a randomized trial." What one will never find in the conclusion section of an RCT is a statement along the lines of, "The group-based conclusions of this study need to be confirmed through case studies of the process and outcome of this intervention with individual clients." (For a recent, epistemologically detailed argument for the required inclusion of systematic case studies in RCT reports, see Dattilio, Edwards, \& Fishman [2010]). Similarly, authors of systematic reviews of the research literature never call for more case studies to be published, to demonstrate the generalizability of meta-analytic findings in the context of individual cases. At the present time, counseling and psychotherapy case studies are mainly read by those who are already convinced of the value of case study methodology. More actively asserting the value of case-based knowledge, to wider audiences, will require case study authors to be more explicit about the rationale on which their truth claims are grounded. It will also force those who are currently not convinced of the value of case-based evidence to be more explicit in articulating their objections. Taken together, these developments have the potential for enabling a dialogue to unfold that will lead to highly useful learning on both sides, greatly enriching the research foundations of the psychotherapy field. 


\section{REFERENCES}

Addis, M. E., \& Krasnow, A. D. (2000). A national survey of practicing psychologists’ attitudes toward psychotherapy treatment manuals. Journal of Consulting and Clinical Psychology, 68, 331-339.

Adler, J.M., \& McAdams, D.P. (2007). The narrative reconstruction of psychotherapy. Narrative Inquiry, 17, 179-202.

Bates, Y. (ed.) (2006). Shouldn't I be feeling better by now? Client views of therapy. London: Palgrave.

Bromley, D. (1986) The case-study method in psychology and related disciplines. New York: Wiley.

Burckell, L.A., \& McMain, S. (2011). Contrasting clients in Dialectical Behavior Therapy for borderline personality disorder: "Marie" and "Dean," two cases with different alliance trajectories \& outcomes. Pragmatic Case Studies in Psychotherapy, 7(2), Article 2, 246267. Available: http://hdl.rutgers.edu/1782.1/pcsp_journal

Corbin, J., \& Strauss, A. (2008). Basics of qualitative research: Techniques and procedures for developing Grounded Theory. $3^{\text {rd }}$ edn. Thousand Oaks, CA: Sage.

Dattilio, F.M., Edwards, D.J.A., \& Fishman, D.B. (2010). Case studies within a mixed methods paradigm: Toward a resolution of the alienation between researcher and practitioner in psychotherapy research. Psychotherapy Theory, Research, Practice, Training, 47, 427441.

Diamond, J. (2010). Intra-island and inter-island comparisons. In J. Diamond, \& J.A. Robinson . (Eds). Natural experiments of history. (pp. 120-141). Cambridge, MA: Belknap Press.

Diamond, J., \& Robinson, J.A. (2010b). Afterword: using comparative methods in studies of human history. In J. Diamond, \& J.A. Robinson . (Eds). Natural experiments of history. (pp. 257-276). Cambridge, MA: Belknap Press.

Diamond, J., \& Robinson, J.A. (Eds)(2010a). Natural experiments of history. Cambridge, MA: Belknap Press.

Dinnage, R. (1988). One to one: Experiences of psychotherapy. London: Penguin.

Dreier, O. (2008). Psychotherapy in everyday life. Cambridge: Cambridge University Press.

Duncan, E.A.S., Nicol, M.M., \& Ager, A. (2004). Factors that constitute a good cognitive behavioural treatment manual: a Delphi study. Behavioural and Cognitive Psychotherapy, 32, 199-213.

Elliott, R. (2002). Hermeneutic Single Case Efficacy Design. Psychotherapy Research, 12, 120.

Elliott, R., Fischer, C.T., \& Rennie, D.L. (1999). Evolving guidelines for the publication of qualitative research studies in psychology and related fields, British Journal of Clinical Psychology, 38, 215-229.

Elliott, R., Partyka, R., Wagner, J., Alperin,R., Dobrenski, R., Messer, S.B., Watson, J.C., \& Castonguay, L.G. (2000). An adjudicated Hermeneutic Single Case Efficacy Design study of experiential therapy for panic/phobia. Psychotherapy Research, 19. 543-557.

Etherington, K. (2000). Narrative approaches to working with adult male survivors of child sexual abuse: The client's, the counsellor's and the researcher's story. London: Jessica Kingsley. 
Faith, M.S., Allison, D.B., \& Gorman, B.S. (1996). Meta-analysis of single-case research. In R.D. Franklin, D.B. Allison, \& B.S. Gorman (Eds). Design and analysis of single-case research. (pp. 245-277). Mahwah, NJ: Lawrence Erlbaum.

Fishman, D.B. (1999) The case for a pragmatic psychology. New York: NYU Press.

Fishman, D.B. (2011). A promising strategy for critically evaluating case studies: Introduction to an issue on the Adjudicated Case Study Method. Pragmatic Case Studies in Psychotherapy, 7(1), Article 1, 1-5. Available: http://hdl.rutgers.edu/1782.1/pcsp_journal

Flyvbjerg, B. (2006). Five misunderstandings about case-study research. Qualitative Inquiry, 12, 219-245.

Flyvbjerg, B. (2001). Making social science matter. Why social inquiry fails and how it can succeed again. New York: Cambridge University Press.

Frommer, J., Reissner, V., Tress, W., \& Langenbach, M. (1996). Subjective theories of illness in patients with personality disorders, qualitative comparison of twelve diagnostic interviews, Psychotherapy Research, 6, 56-69.

Goldman, R. N, Watson, J.C., \& Greenberg, L. S. (2011). Contrasting two clients in EmotionFocused Therapy for depression 2: The case of "Eloise," "It's like opening the windows and letting the fresh air come in." Pragmatic Case Studies in Psychotherapy, 7(2), Article 4, 305-338. Available: http://hdl.rutgers.edu/1782.1/pcsp_journal

Hannan, C., Lambert, M.J., Harmon, C., Nielsen, S.L., Smart, D.W., Shimokawa, K., \& Sutton, S.W. (2005). A lab test and algorithms for identifying clients at risk for treatment failure. Journal of Clinical Psychology, 61, 155-163.

Hatfield, D., McCullough, L., Frantz1, S.H.B., \& Krieger, K. (2010). Do we know when our clients get worse? An investigation of therapists' ability to detect negative client change. Clinical Psychology \& Psychotherapy, 17, 25-32.

Hill, C.E. (1989) Therapist techniques and client outcomes: Eight cases of brief psychotherapy. London: Sage.

Hill, C.E., Sim, W.E., Spangler, P., Stahl, J., Sullivan, T., \& Teyber, E. (2008). Therapist immediacy in brief psychotherapy: Case Study 2. Psychotherapy: Theory, Research, Practice and Training, 45, 298-315.

Iwakabe, S. (2005). Pragmatic meta-analysis of case studies. Annual Progress of Family Psychology, 23, 154-169.

Iwakabe, S. (2011). Extending systematic case study method: Generating and testing hypotheses about therapeutic factors through comparisons of successful and unsuccessful cases. Pragmatic Case Studies in Psychotherapy, 7(2), Article 5, 339-350. Available:

Iwakabe, S., \& Gazzola, N. (2009). From single case studies to practice-based knowledge: Aggregating and synthesizing case studies. Psychotherapy Research, 19, 601-611.

Jacobson, N.S., \& Truax, P. (1991). Clinical significance: A statistical approach to defining meaningful change in psychotherapy research. Journal of Consulting and Clinical Psychologv, 59, 12-19.

Karon, B.P. (2008). An "incurable" schizophrenic: The case of Mr. X. Pragmatic Case Studies in Psychotherapy, 4(1), Article 1, 1-24. http://hdl.rutgers.edu/1782.1/pcsp_journal

Kasper, L.B. Hill, C.E.. \& Kivlighan, D.E. (2008). Therapist immediacy in brief psychotherapy: Case Study 1. Psychotherapy: Theory, Research, Practice and Training, 45, 281-297. 
Pragmatic Case Studies in Psychotherapy, http://pcsp.libraries.rutgers.edu

Volume 9, Module 4, Article 1, pp. 382-402, 12-12-13 [copyright by author]

Kromrey, J.D., \& Foster-Johnson, L. (1996). Determining the efficacy of intervention: The use of effect sizes for data analysis in single-subject research. Journal of Experimental Education, 65, 73-93.

Kuhnlein, I. (1999). Psychotherapy as a process of transformation: the analysis of posttherapeutic autobiographical narrations. Psychotherapy Research, 9, 274-88.

Levitt, H. M., Neimeyer, R. A., \& Williams, D. (2005). Rules versus principles in psychotherapy: Implications of the quest for universal guidelines in the movement for empirically supported treatments. Journal of Contemporary Psychotherapy, 35, 117-129.

Levitt, H., Butler, M., \& Hill, T. (2006). What clients find helpful in psychotherapy: developing principles for facilitating moment-to-moment change. Journal of Counseling Psychology, 53, 314-324.

McLeod, J. (1992). The story of Henry Murray’s diagnostic council: a case study in the demise of a scientific method. Clinical Psychology Forum, 44, 6--12.

McLeod, J. (1997) Narrative and psychotherapy. London: Sage.

McLeod, J. (2010). Case study research in counselling and psychotherapy. London: Sage.

McLeod, J. (2011). Qualitative research in counselling and psychotherapy. 2nd edn. London: Sage.

McNeilly, C.L., \& Howard, K.I. (1991). The Therapeutic Procedures Inventory: psychometric properties and relationship to phase of treatment. Journal of Psychotherapy Integration, 1, 223-234.

Morgan, D.L, \& Morgan, R.K. (2009). Single-case research methods for the behavioral and health sciences. Thousand Oaks, CA: Sage.

Morley, S. (2007). Single case methodology in psychological therapy. In S.J.E. Lindsay, \& G.E. Powell (Eds). A Handbook of Clinical Adult Psychology, 3rd edition. (pp. XX-YY). London: Brunner Routledge.

Morrow, S.L. (2005). Quality and trustworthiness in qualitative research in counseling psychology. Journal of Counseling Psychology, 52, 250-260.

Murray, H.A. (1938). Explorations in personality: A clinical and experimental study of fifty men of college age. New York: Oxford University Press.

Murray, H.A., \& Morgan, C.D. (1945). A clinical study of sentiments. Genetic Psychology Monographs, 32, 3-311.

Najavits, L. M., Weis, R. D., Shaw, S. R., \& Dierbeger, A. E. (2000). Psychotherapists' views of treatment manuals. Professional Psychology: Research and Practice, 31, 404-408.

Nunn, N. (2010). Shackled to the past: the causes and consequences of Africa's slave trades. In J. Diamond, \& J.A. Robinson . (Eds). Natural experiments of history. (pp. 142-184). Cambridge, MA: Belknap Press.

Person, J. B. (2008). The case formulation approach to cognitive-behavior therapy. New York: Guilford.

Seikkula, J., \& Arnkil, T.E. (2006). Dialogical meetings in social networks. London: Karnac.

Stewart, R. E., \& Chambless, D. L. (2010). Interesting practitioners in training in empirically supported treatments: Research reviews versus case studies. Journal of Clinical Psychology, 66, 73-95.

Stiles, W.B. (1993). Quality control in qualitative research. Clinical Psychology Review, 13, 593618. 
Stiles, W. B. (2002) Assimilation of problematic experiences. In J. C. Norcross (ed.) Psychotherapy relationships that work. (pp. 357-365). New York: Oxford University Press.

Stiles, W. B. (2007). Theory-building case studies of counselling and psychotherapy. Counselling and Psychotherapy Research, 7, 122-127.

Stiles, W.B. (2009). Logical operations in theory-building case studies. Pragmatic Case Studies in Psychotherapy, Vol. 5(3), Article 2, 9-22. Available: http://hdl.rutgers.edu/1782.1/pcsp_journal

Strupp, H.H. (1980). Success and failure in time-limited psychotherapy. A systematic comparison of two cases: comparison 1. Archives of General Psychiatry, 37, 595-603.

Stuhr, U., \& Wachholz, S. (2001). In search for a psychoanalytic qualitative strategy: The concept of ideal types. In J. Frommer \& D. L. Rennie (Eds.), Qualitative psychotherapy research: Methods and methodology. (pp. 133-168). Lengerich, Germany: Pabst Science Publishers.

Timulak, L. (2007). Identifying core categories of client identified impact of helpful events in psychotherapy - a qualitative meta-analysis. Psychotherapy Research, 17, 305-314.

Timulak, L. (2009). Meta-analysis of qualitative studies: a tool for reviewing research findings in psychotherapy. Psychotherapy Research, 19, 591-600.

Trijsburg, R.W., Lietaer, G., Colijn, S., Abrahamse, R.M., Joosten, S., \& Duivenvoorden, H.J. (2004). Construct validity of the Comprehensive Therapeutic Interventions rating scale. Psychotherapy Research, 14, 346-366.

Valkonen, J., Hanninen, V., \& Lindfors, O. (2011). Outcomes of psychotherapy from the perspective of the users. Psychotherapy Research, 21, 227-240.

Van den Noortgate, W., \& Onghena, P. (2003). Combining single-case experimental data using hierarchical linear models. School Psychology Quarterly, 18, 325-346.

Wallerstein, R.S. (1986). Forty-two lives in treatment: A study of psychoanalysis and psychotherapy. New York: Guilford Press,

Wallerstein, R.S. (1989). The Psychotherapy Research Project of the Menninger Foundation: an overview. Journal of Consulting and Clinical Psychology, 57, 195-205.

Watson, J.C., Goldman, R.N., \& Greenberg, L.S. (2007). Case Studies in emotion-focused treatment of depression: A comparison of good and poor outcomes. Washington, DC: American Psychological Association.

Watson, J.S., Goldman, R.N., \& Greenberg, L.S. (2011). Contrasting two clients in EmotionFocused Therapy for depression 1: The case of "Tom," "Trapped in the tunnel." Pragmatic Case Studies in Psychotherapy, 7(2), Article 3, 268-304. Available: http://hdl.rutgers.edu/1782.1/pcsp_journal 